Opstelten, W., Essen, G.A. van, Schellevis, F., Verheij, T.J.M., Moons, K.G.M. Gender as an independent risk factor for herpes zoster: a population-based prospective study. Annals of Epidemiology: 2006, 16(9), 692-695

\begin{tabular}{|l|l|}
\hline $\begin{array}{l}\text { Postprint } \\
\text { Version } \\
\text { Journal website }\end{array}$ & 1.0 \\
\hline $\begin{array}{l}\text { Pubmed link } \\
\text { http://linkinghub.elsevier.com/retrieve/pii/S1047279706000123 }\end{array}$ \\
$\begin{array}{l}\text { http://www.ncbi.nlm.nih.gov/sites/entrez?Db=pubmed\&Cmd=ShowDetailView } \\
\text { \&TermToSearch=16516488 }\end{array}$ \\
\hline DOI & $10.1016 /$ j.annepidem.2005.12.002 \\
\hline
\end{tabular}

This is a NIVEL certified Post Print, more info at http://www.nivel.eu

\title{
Gender as an Independent Risk Factor for Herpes Zoster: A Population-Based Prospective Study
}

\author{
WIM OPSTELTEN, MD, PHD, GERRIT A. VAN ESSEN, MD, PHD, FRANCOIS \\ SCHELLEVIS, MD, PHD, EPIDEMIOLOGIST, THEO J.M. VERHEIJ, MD, PHD, AND \\ KAREL G.M. MOONS, PHD, EPIDEMIOLOGIST
}

From the University Medical Center Utrecht, The Netherlands

\begin{abstract}
Purpose: Several studies reported a difference in herpes zoster (HZ) incidence between males and females, but limitations in design and analysis impeded the assessment of gender as an independent risk factor for HZ. This study examines the independent etiologic association between gender and HZ.

Methods: A total of 335,714 persons were observed prospectively during 2001. We registered gender and HZ occurrence, as well as other risk factors for HZ. We calculated overall crude and adjusted odds ratios (ORs) and stratified to age. Results: The HZ incidence in females was 3.9/1000 patients/year $(95 \%$ confidence interval [CI], 3.6-4.2), and in males, $2.5 / 1000$ patients/year $(95 \% \mathrm{CI}$, 2.3-2.8), with a crude OR of 1.53 (95\% CI, 1.36-1.74). After adjustment for potential confounders, the adjusted OR was 1.38 (95\% CI, 1.22-1.56). The incidence was greater in females in the middle-aged (age, 25 to 64 years; OR range, 1.36 to 1.83 ) and youngest group (OR, 1.31; 95\% CI, 0.90-1.89). Gender effect was inverse in young adults (age, 15 to 24 years; OR, 0.64; 95\% CI, 0.41$1.03)$.

Conclusion: Female gender is an independent risk factor for $\mathrm{HZ}$ in the 25- to 64year-old age groups.
\end{abstract}

\section{INTRODUCTION}

Because of the consistency of its gross incidence, herpes zoster (HZ) is used as a proxy for estimating populations in epidemiologic studies (1). HZ is caused by a localized infection with the varicella-zoster virus and represents a recrudescence from a latent phase in which the virus is dormant in sensory ganglia after a primary infection (chicken pox). Age and immunity-attenuating diseases (e.g., malignancy and human immunodeficiency virus [HIV]) are the most well-known risk factors for $\mathrm{HZ} 2,3$ and 4. A recent review showed that several studies reported a difference in $\mathrm{HZ}$ incidence between males and females, but with conflicting results (5). Some found a greater incidence in females 6, 7 and 8. Although most of these studies adjusted gender-specific $\mathrm{HZ}$ incidences for age, they did not adjust for other risk factors for HZ, such as gender differences in immunity-attenuating diseases. 
Opstelten, W., Essen, G.A. van, Schellevis, F., Verheij, T.J.M., Moons, K.G.M. Gender as an independent risk factor for herpes zoster: a population-based prospective study. Annals of Epidemiology: 2006, 16(9), 692-695

Furthermore, females showed a significantly greater consulting rate than males (9), which also could cause a greater reported $\mathrm{HZ}$ incidence in females because of detection bias. Hence, to date, limitations in design, analysis, and study size have impeded the assessment of an independent association between gender and HZ.

A large population-based prospective study of primary care in The Netherlands enabled us to properly quantify whether gender is an independent risk factor for HZ, i.e., adjusted for other risk factors and for gender differences in consulting rates.

\section{METHODS}

Data were derived from a large survey of primary care in The Netherlands in 2001 (10). The total population of this survey comprised $\pm 390,000$ individuals from 104 general practices. This population had a stable size, and its age and gender ratios were similar to those of the general Dutch population. As part of this survey, diagnostic data were extracted from routine electronic medical records in 90 general practices for 1 year, coded in accordance with International Classification of Primary Care codes (11).

For the present analysis, we included data for all subjects who had been observed for a full period of 12 months $(\mathrm{N}=335,714)$. Eighty-seven percent of these subjects were observed from January 1, 2001, to December 31, 2001; the observation period of the remaining 13\% largely covered the year 2001 (10). Their age and gender and whether they had developed a new episode of $\mathrm{HZ}$ were retrieved from the database by using International Classification of Primary Care code S70 ("herpes zoster"). Subsequently, full-text medical records of these selected patients were reviewed to prevent misclassification of the diagnosis of $\mathrm{HZ}$ and assess whether it concerned a new episode of HZ. Based on the literature, we also documented other well-known risk factors for HZ; notably, the presence of diseases that, because of their nature or associated therapy, are potentially immunity attenuating and thus causally related to HZ. These diseases included malignancies, diabetes mellitus, chronic obstructive pulmonary disease, rheumatic disease, and HIV infection. Because only current comorbidity might be relevant for the occurrence of $\mathrm{HZ}$, we exclusively considered concomitant diseases for which a physician-patient contact was registered during the study period.

Finally, we documented for each patient the total number of physician-patient contacts during the study period that were not related to HZ because a high consulting rate may increase the chance of $\mathrm{HZ}$ being detected.

In the analysis, we quantified overall gender-specific $\mathrm{HZ}$ incidence rates, crude rate ratio, and odds ratio (OR) for female gender as a risk factor for HZ. Following one of the largest studies on the topic (8), we then performed a stratified analysis for age, in which we estimated the HZ-gender association across age strata to determine possible interaction by age. Subsequently, we used multivariate logistic regression analysis per age stratum to adjust for possible confounding effects of gender differences in comorbidities and age within the age strata. Obviously, consulting rate is no risk factor for $\mathrm{HZ}$ and thus is not a confounder in the true sense. However, to adjust for the possible effect of gender differences in consulting rate on the gender-HZ association, we finally added the variable "number of physicianpatient contacts" to the multivariate model.

In an additional analysis, we also stratified according to the absence and presence of comorbidities (i.e., malignancy, diabetes, chronic obstructive pulmonary disease, and rheumatic diseases) and assessed per stratum the OR for female gender on risk for HZ, again adjusted for age, other comorbidities, and consulting rate. Because of low numbers, we could not reliably perform this analysis for the HIV subgroup.

\section{Ethical Approval}

The study was carried out according to Dutch legislation on privacy. The privacy regulation of the study was approved by the Dutch Data Protection Authority. 
Opstelten, W., Essen, G.A. van, Schellevis, F., Verheij, T.J.M., Moons, K.G.M. Gender as an independent risk factor for herpes zoster: a population-based prospective study. Annals of Epidemiology: 2006, 16(9), 692-695

\section{RESULTS}

There were 1080 patients with a new diagnosis of HZ. The overall incidence was 3.2/1000 patients per year $(95 \%$ confidence interval [CI], 3.0-3.4). The incidence in females amounted 3.9/1000 patients/year (95\% CI, 3.6-4.2), and in males, $2.5 / 1000$ patients/year (95\% CI, 2.3-2.8; Table 1). The crude incidence rate ratio for female gender in relation to HZ was 1.54 (95\% CI, 1.36-1.74), and the crude OR was 1.53 (95\% CI, 1.36-1.74). In all age groups, $\mathrm{HZ}$ incidence was greater in females, except for subjects in the age range of 15 to 24 years (Table 1 ).

Table 2 lists the distribution of potential confounders (age, comorbidities, and consulting rate) across both genders. Adjustment for these confounders slightly changed most ORs. After adjustment for these confounders, overall $\mathrm{HZ}$ incidence was still greater for females than males (adjusted OR, 1.38; 95\% CI, 1.22-1.56). In the two middle-aged groups (age, 25 to 64 years), adjusted ORs ranged from 1.36 to 1.83 , and also in 0- to 14-year-olds, HZ incidence was greater in females than males (adjusted OR, 1.31; 95\% CI, 0.90-1.89), although not statistically significantly. However, in adolescents (age, 15 to 24 years), female gender was associated inversely with HZ, although borderline significant (adjusted OR, 0.64; $95 \%$ CI, 0.41-1.03). In the oldest age groups ( $\geq 65$ years), $\mathrm{HZ}$ incidences for both genders were almost equal (adjusted OR, $\sim 1.10$ ). Shifting the cutoff values of the age groups indicated similar results and still a male excess in $\mathrm{HZ}$ from age 15 to 30 years (data not shown).

Table 3 lists adjusted ORs for female gender on risk for $\mathrm{HZ}$ in the absence and presence of comorbidity. Female preponderance was present in all comorbidity strata, reflected by adjusted ORs ranging from 1.29 to 1.58 . However, for the presence of each comorbidity, CIs were wider because of relatively low numbers of patients in each stratum, notably for rheumatic diseases.

\section{[TABLE 1, 2 AND 3]}

\section{DISCUSSION}

This is the first prospective study to provide substantial evidence that female gender is associated with the occurrence of HZ, independent of comorbidities and consulting rates. Specifically, the age group of 25 to 64 years shows increased risk for females of contracting $\mathrm{HZ}$, whereas young female adults have a lower risk for contracting HZ.

The age and gender relationship of $\mathrm{HZ}$ remains puzzling. The overall greater $\mathrm{HZ}$ incidence in females was reported previously 6,7 and 8 , as well as the inverse association in young adults 8,12 and 13. Recently, Fleming et al. (8) focused attention on this association, but did not measure and thus did not adjust for potential confounders or gender differences in consulting rates. Because of the size and design of our study, we were able to do so. Female preponderance also was observed in the incidence of herpes simplex (8), supporting the hypothesis that women respond differently from men to latent alphaherpesvirus infections. However, a recent study showed that external reexposure to the varicella-zoster virus (contact with patients with chicken pox) would protect latently infected individuals against HZ (14). Accordingly, females would have a lower risk than males for contracting HZ because they are likely to be exposed more frequently to children with chicken pox. This protection by repeated exposure to varicella possibly could invert the gender effect in young adults. However, because mean childbearing age in The Netherlands presently is 29 years, this protection only partly explains the male excess in young adults. Probably other, still unknown, gender- and age-related factors are associated with susceptibility for HZ.

The observed HZ incidence in this study is consistent with earlier published data 13 and 15. Moreover, crude HZ incidences across age strata equal the data from Fleming et al. (8). This also applies to reported prevalences of comorbidities across both genders 16, 17 and 18 . 
Opstelten, W., Essen, G.A. van, Schellevis, F., Verheij, T.J.M., Moons, K.G.M. Gender as an independent risk factor for herpes zoster: a population-based prospective study. Annals of Epidemiology: 2006, 16(9), 692-695

Therefore, data from our study and estimated associations between female gender and $\mathrm{HZ}$ incidence seem reliable.

Some potential limitations of this study need to be addressed to appreciate the results. First, because almost all zoster cases had been diagnosed by general practitioners without virologic confirmation, some cases (e.g., herpes simplex) might have been misdiagnosed as zoster. This was reported previously 7 and 19 . However, because this diagnostic error is nondifferential to gender, it will not affect the association between zoster and gender. Second, some other studies suggested (although not yet properly quantified) the existence of other potential risk factors for HZ, such as psychologic stress and mechanical trauma (5). Unfortunately, these variables were not assessed in our patients. However, it is unlikely that possible residual confounding caused by these and other unmeasured risk factors would completely dilute the adjusted ORs in our study to 1.0.

From a method point of view, it could be questioned whether gender should be regarded a risk factor for $\mathrm{HZ}$ or an effect modifier of the effect of the varicella-zoster virus on $\mathrm{HZ}$. Because the virus is the only and direct causative agent for the occurrence of HZ, one could argue that any other influential factor (such as comorbidity and gender) modifies the association between the virus and $\mathrm{HZ}$ occurrence. Conversely, $\mathrm{HZ}$ will not occur without a waning virus-specific immunity, which is reflected by several proxies (such as comorbidity). In this perspective, gender could be viewed as a risk factor for HZ. We note that in both instances, the analytic approach would be the same because each individual has the etiologic factor (i.e., the varicella-zoster virus) present.

In conclusion, results of this study confirm that female gender independently increases risk for $\mathrm{HZ}$ in the 25- to 64-year age groups.

\section{REFERENCES}

1. Fleming DM, Bartelds A, Chapman RS, Cross KW. The consistency of shingles and its significance for health monitoring. Eur J Epidemiol. 2004;19:1113-1118.

2. Brisson M, Edmunds WJ, Law B, Gay NJ, Walld R, Brownell M, et al. Epidemiology of varicella zoster virus infection in Canada and the United Kingdom. Epidemiol Infect. 2001;127:305-314.

3. Morens DM, Bregman DJ, West CM, Greene MH, Mazur MH, Dolin R, et al. An outbreak of varicella-zoster virus infection among cancer patients. Ann Intern Med. 1980;93:414-419.

4. Alliegro MB, Dorrucci M, Pezzotti P, Rezza G, Sinicco A, Barbanera M, et al. Herpes zoster and progression to AIDS in a cohort of individuals who seroconverted to human immunodeficiency virus. Italian HIV Seroconversion Study. Clin Infect Dis. 1996;23:990-995.

5. Thomas SL, Hall AJ. What does epidemiology tell us about risk factors for herpes zoster? Lancet Infect Dis. 2004;4(1):26-33.

6 . Wilson JB. Thirty one years of herpes zoster in a rural practice. $\mathrm{Br}$ Med J. 1986;293:1349-1351.

7. Helgason S, Sigurdsson JA, Gudmundsson S. The clinical course of herpes zoster: A prospective study in primary care. Eur J Gen Pract. 1996;2:12-16. 8. Fleming DM, Cross KW, Cobb WA, Chapman RS. Gender difference in the incidence of shingles. Epidemiol Infect. 2004;132:1-5.

9. Rowlands $\mathrm{S}$, Moser K. Consultation rates from the general practice research database. Br J Gen Pract. 2002;52:658-660.

10. Westert GP, Schellevis FG, de Bakker DH, Groenewegen PP, Bensing JM, van der Zee J. Monitoring health inequalities through general practice:

The Second Dutch National Survey of General Practice. Eur J Public Health. 2005;15:59-65.

11. Lamberts $\mathrm{H}$, Wood M, Hofmans-Okker J. The International Classification of Primary Care in the European Community. Oxford: Oxford University Press; 1993. 
Opstelten, W., Essen, G.A. van, Schellevis, F., Verheij, T.J.M., Moons, K.G.M. Gender as an independent risk factor for herpes zoster: a population-based prospective study. Annals of Epidemiology: 2006, 16(9), 692-695

12. Ragozzino MW, Melton LJ III, Kurland LT, Chu CP, Perry HO. Populationbased study of herpes zoster and its sequelae. Medicine (Baltimore).

1982;61:310-316.

13. Hope-Simpson RE. Postherpetic neuralgia. J R Coll Gen Pract.

1975;25:571-575.

14. Thomas SL,Wheeler JG, Hall AJ. Contacts with varicella or with children and protection against herpes zoster in adults: A case-control study. Lancet. 2002;360:678-682.

15. Donahue JG, Choo PW, Manson JE, Platt R. The incidence of herpes zoster. Arch Intern Med. 1995;155:1605-1609.

16. Beeson PB. Age and sex associations of 40 autoimmune diseases. Am J Med. 1994;96:457-462.

17. Mooy JM, Grootenhuis PA, de Vries H, Valkenburg HA, Bouter LM, Kostense $\mathrm{PJ}$, et al. Prevalence and determinants of glucose intolerance in

a Dutch Caucasian population. The Hoorn Study. Diabetes Care. 1995;18:1270-1273.

18. Pauwels RA, Rabe KF. Burden and clinical features of chronic obstructive pulmonary disease (COPD). Lancet. 2004;364:613-620.

19. Kalman CM, Laskin OL. Herpes zoster and zosteriform herpes simplex virus infections in immunocompetent adults. Am J Med. 1986;81:775-778.

\section{TABLES}

TABLE 1. Incidence of herpes zoster by age and gender per 100,000 person-years; crude and adjusted odds ratios with $95 \%$ Cls for female gender on risk for herpes zoster

\begin{tabular}{|c|c|c|c|c|c|c|c|c|}
\hline \multirow{2}{*}{$\begin{array}{l}\text { Age groups } \\
\text { (years) }\end{array}$} & \multicolumn{2}{|c|}{$\begin{array}{c}\text { Females } \\
(n=168,527)\end{array}$} & \multicolumn{2}{|c|}{$\begin{array}{c}\text { Males } \\
(n=167,187)\end{array}$} & \multicolumn{2}{|c|}{ Crude odds ratio } & \multicolumn{2}{|c|}{ Adjusted odds ratio } \\
\hline & Cases & Incidence & Cases & Incidence & $\mathrm{F} / \mathrm{M}$ & $95 \% \mathrm{Cl}$ & $\mathrm{F} / \mathrm{M}$ & $95 \%$ व \\
\hline $0-14$ & 63 & 219 & 51 & 166 & 1.32 & $0.91-1.91$ & 1.31 & $0.90-1.89$ \\
\hline $15-24$ & 35 & 171 & 45 & 218 & 0.78 & $0.51-1.22$ & 0.64 & $0.41-1.03$ \\
\hline $25-44$ & 115 & 218 & 78 & 142 & 1.53 & $1.15-2.04$ & 1.36 & $1.01-1.83$ \\
\hline $45-64$ & 264 & 633 & 139 & 320 & 1.97 & $1.60-2.42$ & 1.83 & $1.48-2.25$ \\
\hline $65-74$ & 78 & 588 & 59 & 517 & 1.14 & $0.81-1.60$ & 1.10 & $0.78-1.55$ \\
\hline $75+$ & 101 & 857 & 52 & 780 & 1.10 & $0.79-1.54$ & 1.09 & $0.77-1.53$ \\
\hline Overall & 656 & 389 & 424 & 254 & 1.53 & $1.36-1.74$ & 1.38 & $1.22-1.56$ \\
\hline
\end{tabular}

$\mathrm{CI}=$ onfidence interval.

TABLE 2. Distribution of potential confounders of the association between gender and herpes zoster

\begin{tabular}{|c|c|c|c|}
\hline Potential confounders & $\begin{array}{c}\text { Females } \\
(n=168,527)\end{array}$ & $\begin{array}{c}\text { Males } \\
(n=167,187)\end{array}$ & $p$ \\
\hline Mean age (years) & $38.9 \pm 22.2$ & $36.9 \pm 20.9$ & \\
\hline Malignancy & $1,336(7.9)$ & $732(4.4)$ & $<0.001^{a}$ \\
\hline Diabetes mellitus & $4,715(28.0)$ & $4,123(24.7)$ & $<0.001^{a}$ \\
\hline $\begin{array}{l}\text { Chronic obstructive } \\
\text { pulmonary disease }\end{array}$ & $1,636(9.7)$ & $2,082(12.5)$ & $<0.001^{\mathrm{a}}$ \\
\hline Rheumatic disease & $1,131(6.7)$ & $539(3.2)$ & $<0.001^{a}$ \\
\hline $\begin{array}{l}\text { Human immunodeficiency } \\
\text { virus infection }\end{array}$ & $12(0.1)$ & $27(0.2)$ & $0.02^{\mathrm{a}}$ \\
\hline Consulting rate ${ }^{b}$ (number/year) & $3(1-7)$ & $2(0-4)$ & $<0.001^{\mathrm{c}}$ \\
\hline
\end{tabular}

Figures are number of patients (promillage) or mean \pm SD unkss stated otherwise. Chi-square test.

Median (25th to 75 th percentik).

Mann-Whitney $U$ test.
TABLE 3. Odds ratio with $95 \%$ confidence intervals for female gender on risk for herpes zoster in strata of (the presence and absence of) comorbidities and adjusted for age and other comorbidities

\begin{tabular}{lcc}
\hline & \multicolumn{2}{c}{ Adjusted odds ratio } \\
\cline { 2 - 3 } Comotbidity & F/M & $95 \%$ Confidence interval \\
\hline Malignancy & & \\
$\quad$ Absent $(n=353,646)$ & 1.37 & $1.20-1.55$ \\
$\quad$ Present $(n=2068)$ & 1.58 & $0.62-4.05$ \\
Diabetes mellitus & & \\
$\quad$ Absent $(n=346,876)$ & 1.37 & $1.21-1.56$ \\
$\quad$ Present $(n=8838)$ & 1.29 & $0.72-2.34$ \\
Chronic obstructive pulmonary disease & & \\
$\quad$ Absent $(n=351,996)$ & 1.37 & $1.20-1.55$ \\
$\quad$ Present $(n=3718)$ & 1.47 & $0.79-2.75$ \\
Rheumatic disease & & \\
$\quad$ Absent $(n=354,044)$ & 1.37 & $1.21-1.56$ \\
Present $(n=1670)$ & 1.52 & $0.41-5.60$ \\
\hline
\end{tabular}

